Article

\title{
Feeling the Service Product Closer: Triggering Visit Intention via Virtual Reality
}

\author{
Ali Yuce ${ }^{1, *(\mathbb{D}}$, Huseyin Arasli ${ }^{2}$, Ali Ozturen ${ }^{1}$ and Mustafa Daskin ${ }^{3}$ \\ 1 Faculty of Tourism, Eastern Mediterranean University, Famagusta 99628, North Cyprus, Mersin 10, Turkey; \\ ali.ozturen@emu.edu.tr \\ 2 The Norwegian School of Hotel Management, University of Stavanger, 4036 Stavanger, Norway; \\ huseyin.arasli@uis.no \\ 3 Tourism Department, Amasya University, Amasya 05100, Turkey; daskinmus@hotmail.com \\ * Correspondence: aliyuc@gmail.com
}

Received: 22 July 2020; Accepted: 11 August 2020; Published: 17 August 2020

check for updates

\begin{abstract}
This study examines the essential characteristics of Virtual Reality (VR) that influence individual visit intention towards a touristic product. Despite the extensive research about VR, however, only little has examined the impact of factors that alter customers' attitudes and trigger purchasing intention. This study applied Information Systems Success Model and conducted a survey using the convenience sampling method with international tourists who visited North Cyprus. The data were analyzed using the Partial Least Squares Structural Equation Modeling (PLS-SEM) technique, and findings demonstrated that VR has great potential to influence visitors' final destination by promoting tourism products and services. This paper revealed that VR-as a marketing medium — creates positive impacts and stimulates individuals' intentions to visit a destination. The study provides implications for tourism sector actors such as tourism planners, policymakers, travel agencies, and hotel managers as well as prosocial guest experience to improve their marketing strategies.
\end{abstract}

Keywords: virtual reality; VR; IS Success Model; emerging technologies; tourism; destination; intention; perception; marketing; planning; PLS-SEM

\section{Introduction}

Tourism has been a critical economic source for developing countries. Its importance is even more vital for countries like North Cyprus. This small country's economy heavily depends on tourism [1-3]. However, the country has not been in the center of the tourism industry due to political issues and lack of marketing and promotion strategies [4-6]. The local and national authorities seek alternative plans and approaches to attract investors for tourism growth so that they can receive more touristic activities in their area. More tourist visitation has significant meaning because it results in economic growth in many vital areas, such as employment opportunities, improving the infrastructure of the country, and generating more exchange. In this sense, adoption and implications of the emerging technologies may take the role of influencing the potential tourists to make an impact on the tourism industry in the countries that are desperate to promote their tourism attractions.

The ongoing digital transformation and revolution have been influencing our economic, social, and cultural experiences in myriad ways from traditional communication practices and activities to the way of performing our work [7,8]. Innovation efforts, in particular in emerging technologies, have been a driving force in all businesses. Adapting and staying up to date with emerging technologies, despite the fact that a new technology's life does not last too long, helps to reduce operational costs and ensure businesses reach their highest potential [9]. Moreover, engaging with the most current emerging 
technologies also greatly influences business partners to provide more efficient and quality customer services in the tourism industry [10]. On the other hand, digital transformation originating in a new technology is only a portion of an organization's overall strategy to survive in a highly competitive world [11]. The question is what type of technology should be developed and implemented to catalyze touristic activities. One needs to clarify two significant points to implement new technology in the field [12]. The first one is understanding the sector in depth and the other one is how the proposed technology is related to the sector [12]. Then one can expect to have the utmost benefit of the desired technology. The tourism industry heavily depends on technology for the nature of its operational business processes $[8,13]$. There are numerous studies in the literature which indicate that technologies such as smartphones [14], websites [15], and augmented reality [16] trigger potential users' attitude and decision-making process to visit a destination. There are several studies [17-19] which also investigated the impact of VR in the tourism field. However, neither of these studies investigated the role of VR by implementing the Information Systems (IS) Success Model to look into the deeper relationship between tourism products and technology in terms of information quality, system quality, and service quality towards intention to visit. Hence, this study aims to contribute to the existing literature by revealing the technical factors in alignment with emotional factors that influence users' satisfaction toward destination visiting intention.

Virtual reality is one of the most novel technological innovations that can have a significant impact on the tourism sector in many different ways. VR can influence potential customer intentions in selecting a tourism product and improve their satisfaction through their visit [20]. VR with higher immersed technology has great potential for the promotion of the country by appealing the users with the VR. In recent years, it has been observed that as VR applications/software advance, the availability of VR-related applications and contents increases. "The availability of low cost of VR viewers such as Google Cardboards and the abundance of tourism-related VR content make it easier for anyone to experience virtual tours of cities and tourist attractions from anywhere in the world" [20].

$\mathrm{VR}$ is one of the advanced technologies that offer enormous opportunities for the majority of the stakeholders in terms of creating long-term achievable benefits. Developing suitable development plans that clearly explain the relationships between the needs and values of the tourism industry and predicted technology enhances the opportunity to ensure long-term value creation. Despite some of the plan developers who prefer short-term interests over the long-term benefits, long-term value creation has been one of the major concepts of the sustainable tourism in the literature. Implementing the right technology at the right time in the tourism sector helps to achieve the long-term goals and benefits by extending the lifetime of the tourism products. Therefore, the integration of advanced technology with the sustainable tourism phenomenon will promise more convincing preservation of socioeconomic, cultural, and environmental values of touristic destinations around the globe. Furthermore, VR assures that tourism sites, whether they are the most or least sensible destinations, can all be visited virtually without actually being in the same physical environment.

The literature is devoid of theoretical and practical evidence of factors leading to user satisfaction and travel intention for a destination. In an attempt to understand what features of VR trigger customer intention, this study draws on an Information Systems Success (ISS) model [21] to answer the following research questions:

What role do (a) VR information quality, (b) VR System quality, and (c) service quality play in explaining a VR user's satisfaction?

What role does VR user satisfaction play in shaping users' intention to visit the destination?

Does VR user satisfaction mediate the association between (a) VR information quality, (b) VR system quality and (c) service quality and VR users' satisfaction?

Investigating such a relationship between these variables would have numerous benefits not only for the literature (theoretical) but also for the industry (practical). Findings can help tourism agencies, hotel managers, policymakers, planners, and authorities to improve their marketing strategies and 
attract more visitors to their touristic attractions. Using VR in the real-world environment would also improve overall customer satisfaction.

\section{Virtual Reality}

Virtual reality, as one of the latest innovative technological tools, has been one of the paramount emerging technologies which has excellent potential to make significant achievements in the lives of the people and organizations $[7,22,23]$. VR also has been the interest of multidiscipline areas such as education, art, psychology, entertainment, and marketing [22,24]. VR can be defined as a gadget that allows the users to feel and react to the stimulated/depicted (virtual) environment with all the senses as if they are in the actual place $[19,25]$. In other words, VR can be seen as a device that makes a dream come true by moving us to the virtual world, without actually leaving a physical place, by fooling the brain [26]. VR's implementation in real-life situations began influencing the organizational progress, user satisfaction and engagement, in particular after integrating the portable VR headsets with smartphones, in which VR contents and applications are found quickly. The adaptation of emerging technologies, including VR, does not only help organizations to keep up with the current or advanced technologies for marketing, communication, psychology and business operations but also helps them for entertainment and training purposes [8,27]. The constant development of information, communication, and virtual reality technologies promise common implementation areas throughout the tourism sector $[18,28]$. However, it demands careful consideration and planning to discover what factors influence consumers' desire to purchase tourism products.

There are two major types of virtual reality: (a) tethered, which is connected to the personal computer, server, or digital platform. The second one is called (b) untethered, and it is mobilized so that it does not require any digitalized station. Nevertheless, in any form, virtual reality is composed of software and hardware with a mobile headset or glasses. VR is usually defined as a computer-generated platform that creates the sense of being in an environment as if individuals are in a real-life context [29]. Virtual reality is based on the factor that creates a cognitive connection with realistic images and videos. Cognitive connections with the presence phenomenon occur as a result of interacting with the VR environment [30]. VR illustrates images, videos, games, and movies in a 3D format that makes an impact on user perceptions that makes them feel like they are in the depicted location [24,31]. VR allows users to control the system by physical movement, speech, or text that depends on the user's characteristics, preferences, and the goal of the platform. The sense of presence that is created by VR is the primary element that serves as a motivator for a particular attitude or behavior $[24,30]$. However, as stated in [32], identifying the factors or characters of VR technology will improve the users' perceptions towards the products and services.

\section{Theoretical Background and Hypotheses Development}

\subsection{Information Systems (IS) Success Model}

The Information Systems (IS) Success Model has been a useful measurement tool, and it has been used pervasively with several topics in various fields, including emerging technologies [33-35]. ISS was first introduced by DeLone and McLean (1992) to evaluate the functionality and practicability of a medium in terms of what value it adds, to what degree it achieves the desired goals and improves overall quality and satisfaction of a system and a device in the context of industry standards [35,36]. The IS Success Model was updated in 2003 [21,37-40]. The fundamental difference between the two versions is the "service quality" dimension in the updated model [21]. Service quality, along with the rest of the variables of the IS model, helped to measure the "effectiveness level" [41] or "influence level" [42] of the information system and proposed device. Discovering the "net benefits", which used to be "organizational impacts" in the original model, of a system does not only validate how beneficiary it is for the organization, but it also helps the researchers identify the drawbacks to determine the final positive outcomes of the system/product [21,37]. 
The Information Systems (IS) Success Model helps to avoid the possible speculations and biases about the real impacts of the dependent variable(s) to ensure that the variable's effectiveness is measured objectively and accurately. Hence, this study tested the proposed model using VR in a real situation with real people to confirm its functionality and its impact on users by focusing on the three significant constructs (quality of information, system, and service) of the IS Success Model. The findings will not only contribute theoretically, but they will also provide healthier guidance for managerial implementations.

\subsection{VR Information Quality and Satisfaction}

Delone and McLean (2003) stated that the 'semantic success' of a medium is essential to assessing the value of the delivered message via a technological tool. In other words, how accurate, meaningful and adequate the perceived images are are the key elements that indicate the quality of the information. VR transmits the information to the users with simulations in a virtual environment that creates the sense of presence as if they are moving to the depicted object/place virtually without detaching from the physical real place or environment [43]. The success of the entire project is achieved through the degree of participants' captivation, reaction, and response to the depicted virtual environment or simulation. How successful the given information is besides system and service quality is crucial to increasing the applicability and benefits of this innovative medium [40]. In light of this, information quality, as one of the most critical dimensions of the IS Success model, helps to measure how precise, timely, secure, appropriate and available the information that is being conveyed to the users by the information system is [44,45]. Information quality is measured based on the given information's reliability, comprehensibility, and completeness [21,44]. On the other hand, Gorla et al. (2010) argued that information quality is measured with some critical measures such as how was the overall satisfaction of the medium in terms of information quality, clarity, and relevancy to the intended goal or object. Satisfaction refers to the pleasant or unpleasant experience level of the participants as a result of interacting with the virtual environment [45]. The better quality and adequacy information delivered via the VR, the higher the satisfaction that one can get. Hence, the paper posits that:

Hypothesis 1 (H1). VR information quality delivered to VR users has a significant positive impact on perceived satisfaction.

\subsection{VR System Quality and Satisfaction}

System quality refers to how comfort, consistency, user-friendliness, accessibility, and response rate goals are achieved during user experiences related to the presented medium such as a virtual reality environment $[45,46]$. VR systems should be prepared, designed, and implemented in a way that should be easy to use by individuals at all skill levels. A potential customer or user should be able to adapt the system efficiently and effectively so that it would keep them motivated and engaged through personalized information that is accessed at high speed [40]. In other words, regardless of how brilliant the information is, if it does not transmit information effectively, accurately, and precisely using a reliable and user-friendly system this can pose a high risk to achieving the desired goals of the implemented system [47]. Hence, virtual reality should be designed and prepared to ensure that the system offers useful, customizable, maintainable, and reliable content for the end-users [44]. A tangible measurement can help to forestall future issues within a system to provide more achievable and workable outputs and create greater user satisfaction. Therefore, we hypothesize that:

Hypothesis 2 (H2). VR System Quality delivered to VR users has a significant positive impact on perceived satisfaction. 


\subsection{VR Service Quality and Satisfaction}

Service quality indicates whether customers' expectations are achieved or not using the provided services of the presented model. The most important characteristics are the service's reliability, availability, and integrity [44,48]. Virtual system effectiveness cannot only be evaluated with the information or system quality that customers experience as they interact with the system. It is crucial to ensure that users are supported and guided with effective service as they interact with the system. Providing efficient and reliable service for users is important due to their lack of familiarity with current technologies. Therefore, it requires individuals who are well aware of the system and information to provide a novel virtual reality experience for the user. In order to understand the overall tangible and intangible benefits of VR, the service quality dimension of the IS success model should be evaluated for its effectiveness of the information system success with an empirical study. On the other hand, the lack of service quality, such as the level of assistance, guidance, timely given feedback may result in the dissatisfaction of the users towards the system [40]. Because service quality has a tremendous impact on user satisfaction, this study hypothesizes that:

Hypothesis 3 (H3). VR Service Quality delivered to VR users has a significant positive impact on perceived satisfaction.

\subsection{VR Satisfaction and Intention to Visit}

User satisfaction is seen as a lifeline for service firms. User satisfaction refers to how successfully the desired information is delivered to the users via the designed system or offered a device. A satisfied user is the one who is more likely to have intention towards the depicted destination. It also ensures that needs are fulfilled with the given reliable information thru the user-friendly system and well-prepared individuals.

Furthermore, it is vital to discover if satisfaction is achieved or not. Subsequently, if it is achieved, then it should be discovered to what extent it affected the users' decision, attitude, and emotion for future use. Unlike some studies $[39,49]$ in which user satisfaction is measured indirectly, this study focuses and measures the causal relationship between information quality, system quality, service quality, and user satisfaction. As a result of the quality of information, quality of system and service, it is expected to have customers or users with a positive and constructive attitude towards the VR system. If the designed system captures the attention of users and creates adequate satisfaction, then it is expected to make a significant shift on the users' visitation intention. Hence, we proposed the hypothesis that:

Hypothesis 4 (H4). VR User satisfaction has a significant positive impact on the intention to visit.

\subsection{The Mediating Role of Satisfaction}

Satisfaction is defined by Lu, Kuo [50] "as a consumer's positive judgement about the features of a product or service [51], and as the overall effective attitude and cognitive evaluation of the level of pleasure felt towards an IS application by someone who interacts with it directly" [52,53]. Although it is a challenging task being able to measure user satisfaction, due to its complex and multilevel relationship with different constructs, the ability to measure the satisfaction level can contribute to discovering the summative and formative evaluations of the desired information systems [54]. Summative evaluation refers to how given constructs influence the users' attitude and behavior in terms of their satisfaction level. On the other hand, formative evaluation refers to whether this altered behavior is formed or established enough for the desired outcome or not [54]. An information system's success is closely related with user satisfaction in terms of increasing their "intention to continue using (continuance) information systems" or services $[34,55]$ or purchasing the product. There is a significant relationship between innovative information, visitor attitude, and destination selections. Wang, Park [14] argued 
that tourists are "hedonic pleasure seekers" and their needs are fulfilled with mobile apps that lead to greater satisfaction.

Satisfaction as a mediator is an important indicator to determine whether antecedents of customer satisfaction are associated with the visit intentions or not. One notable study by Chiu, Chiu [34] revealed that satisfaction has a significant mediating role between the IS success model and intention for using the web-based learning platform. However, whether the mediation role of satisfaction influences the potential VR users' decision regarding the intention to visit a destination has not been measured in the existing literature. In light of the aforesaid theoretical and empirical arguments, this study proposed that there is a significant relationship between the predictors, which are information quality, system quality, and service quality, and intention to visit through the mediation effect of the satisfaction. The hypotheses are proposed as follow:

Hypothesis 5a (H5a). Perceived satisfaction with VR mediates the effect of VR information quality on the intention to visit.

Hypothesis $\mathbf{5 b} \mathbf{( H 5 b ) . ~ P e r c e i v e d ~ s a t i s f a c t i o n ~ w i t h ~ V R ~ m e d i a t e s ~ t h e ~ e f f e c t ~ o f ~ V R ~ s y s t e m ~ q u a l i t y ~ o n ~ t h e ~ i n t e n t i o n ~}$ to visit.

Hypothesis 5c (H5c). Perceived satisfaction with VR mediates the effect of VR service quality on the intention to visit.

\subsection{The Study Model}

There has been a need to discover the real impacts of an information system's success of digital or non-digital electronic devices in terms their consistency and suitability for the goal of the organizations (Petter et al., 2008). As Guttentag (2010) cited from Gutierrez, Vexo, and Thalmann (2008), VR engages the user physically and psychologically. Both functionalities depend on the quality of the system, information, and service. The more durable and more explicit the information quality, system quality, and service quality are, the greater satisfaction of the presented information system for the users (Wang and Liao, 2008). Hence, the IS Success Model with its borrowed metrics for this study can help to discover some critical aspects such as the concrete and elusive advantages of VR and the contributions to the tourism sector.

This study aims to test the proposed model (see Figure 1) to assess the impact of antecedents and the mediating role of perceived satisfaction of VR.

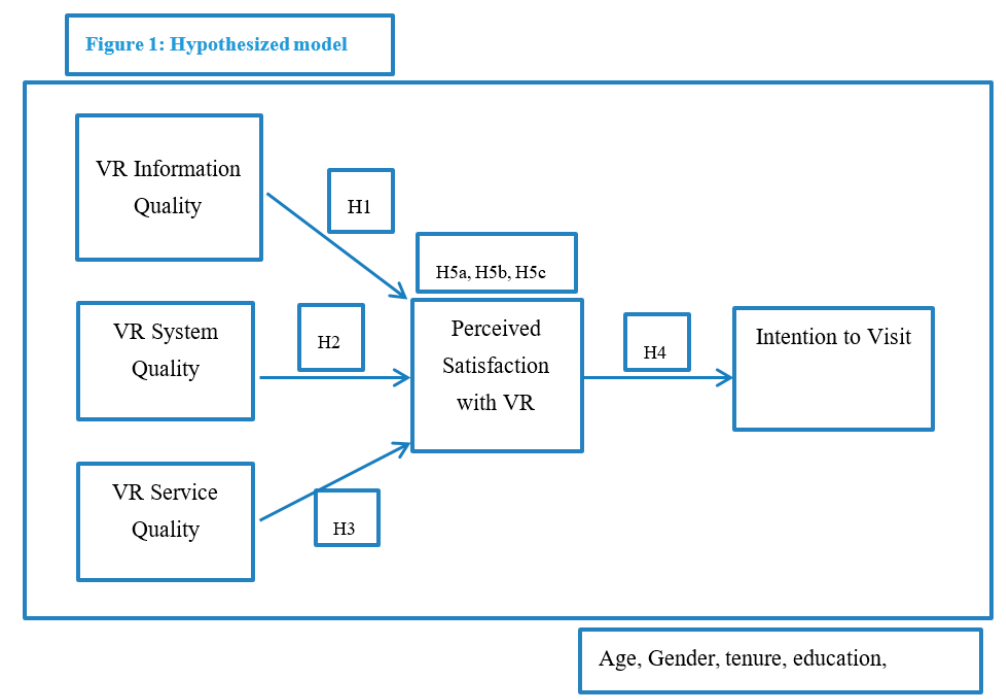

Figure 1. Study Model. 


\section{Methodology}

\subsection{Sample and Procedure}

For this empirical study, data were collected from a diverse group of international tourists in North Cyprus. One of the significant problems of North Cyprus is the lack of efficient marketing strategies due to the economic and political issues this country has faced. However, recent innovational technological advancements with lower cost and more powerful features offer alternative approaches to overcome these challenges than traditional marketing tools. Cyprus receives an average of 300,000 tourists from various countries other than Turkey and its bed capacity has been growing continuously. According to the Turkish Republic Northern Cyprus Tourism Ministry reports, a total of 249,079 in 2016, 348,471 in 2017, 317,434 in 2018 and 336,184 foreigners except Turkish visitors stayed in Northern Cyprus. The same report also indicates that a total of 25, 570 beds were available as of June 2019 in Northern Cyprus [56].

This study used the convenience sampling method of the nonprobability technique method to enhance the reliability and validity of the study. Each individual was selected based on their availability and had an equal chance to join with this study among a large group of the population. Convenience selection allowed to recruit the participants without categorizing them under a specific term to eliminate possible biases and classification error. The researchers conducted a pilot study with 15 international tourists to test the clarity and consistency of the items by targeting several international tourists in Famagusta, North Cyprus (see Figure 2) [57]. North Cyprus is the third largest island in the Mediterranean Sea, and tourism is the primary source of income for this island [1,3]. This study targeted international tourists who visited Famagusta, North Cyprus. The researchers focused on travel agencies, churches, and other attractions, such as hotels, to conduct the study in the life-like environment in Famagusta. They contacted the agency owners and other authorities to give them detailed information about the aim and scope of this research.

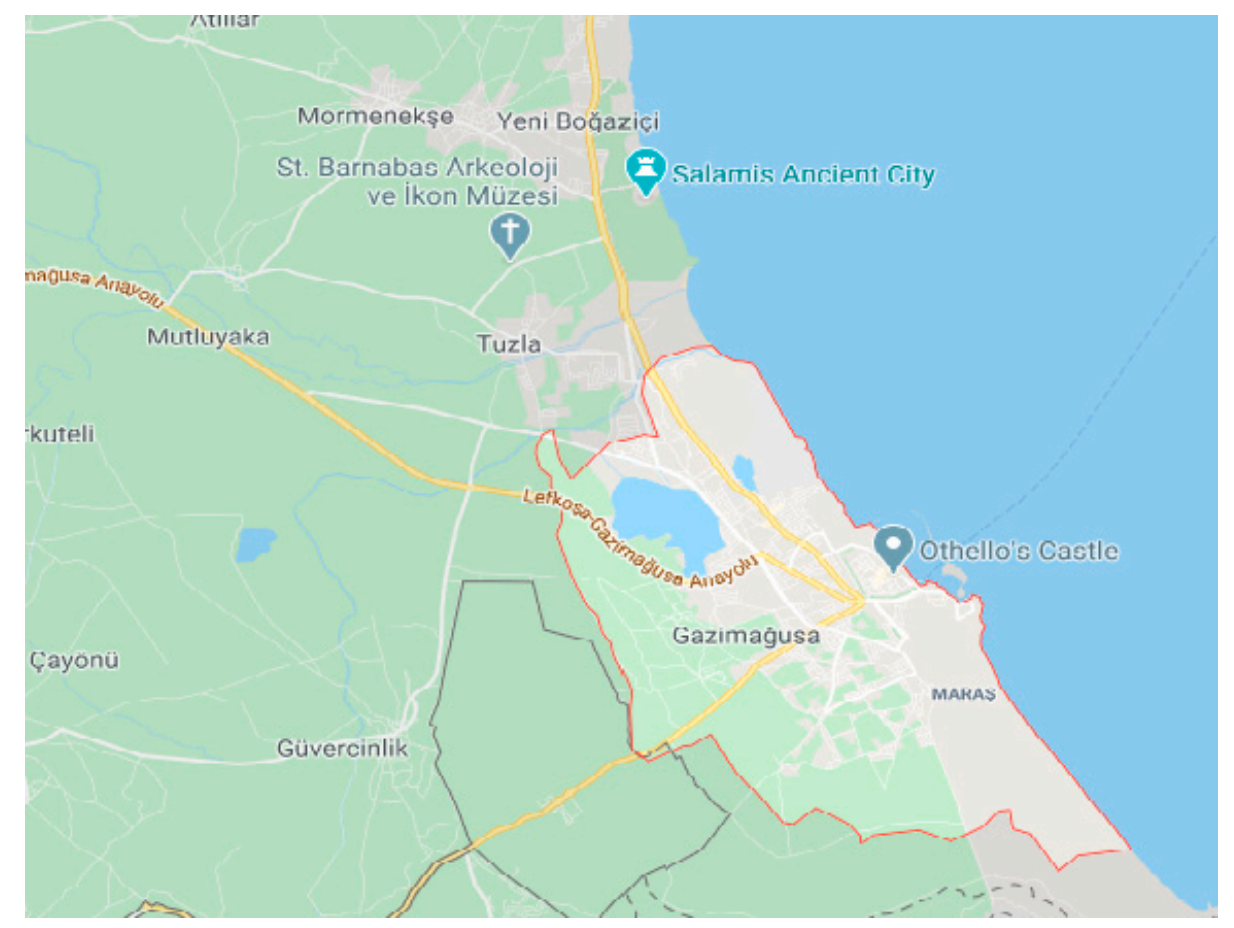

Figure 2. Famagusta.

Participants were given head-mounted VR glasses, and their experience lasted about $10 \mathrm{~min}$. They kindly responded to the self-administered questionnaire, and then they placed the questionnaire in a basket. A total of 229 questionnaires were distributed among the international tourists, and 217 
of them were collected. The majority of the target population consisted of various nationalities and cultures. It is essential to collect data from a diverse group of individuals to develop better solutions and approaches that will help to enhance the touristic benefits for the destinations and improve visitors' satisfaction. The majority of participants were young people since they tend to use emerging technologies.

Nevertheless, 12 of the questionnaires were discarded due to incomplete information at different categories of the questionnaire. Finally, 205 of the questionnaires were analyzed with a response rate of $89.5 \%$. The hypotheses, as mentioned earlier, were tested to determine whether VR has any significant impact on visit intention. All adapted items were initially in English. Thus, there was no need to use the back-translation method. As it was mentioned above, the pilot study indicated that participants had no difficulties in responding to the prepared questions.

\subsection{Questionnaire Development and Measures}

The first page of the questionnaire notified the participants of the aim and scope of the study. It also ensured that the participants' anonymity and confidentiality were preserved for the reliability of the study. The first page also allowed the participants to answer the items related to the information quality, system quality, and service quality of the IS Success Model. The intuitive/perceptual constructs were measured with multiple items that were used in previous studies in the relevant literature.

Four items to measure the Information Quality (IQ) were adapted from previous studies $[21,34,40,45,58]$ using the 5-point Likert scaling system. A higher score indicated greater perceived information quality.

Three items to measure the System Quality (SQ) were adapted from previous studies (Chiu, Chiu, and Chang, 2007; Seddon and Kiew, 1996) using a 5-point Likert scaling system. A higher score indicated greater perceived system quality.

Three items to measure the Service (SEQ) were adapted from previous studies (Delone and McLean, 2003; Seddon and Kiew, 1996) using the 5-point Likert scaling system. A higher score indicated greater perceived service quality.

VR Satisfaction was measured with items that were adapted from Liaw, Chen [59] and [60] using the 5-point Likert scaling system. A higher score indicated greater perceived VR satisfaction. Finally, the criterion variable, which is visit intention, was measured with three items that were adapted from Kozak and Rimmington [61], and Tussyadiah [62] using the 5-point Likert scaling system. A higher score indicated greater perceived visit intention.

\subsection{Data Analysis}

This paper applied a partial least squares (PLS) path modeling-based algorithm [63] to evaluate the structure of the proposed model (Figure 1). The PLS algorithm is designed and created by Wold [64] as a newer version of structural equation modeling (SEM) approach. PLS has been applied in numerous studies $[65,66]$. Confirmatory factor analysis (CFA) is applied besides PLS in this study to investigate the dimensionality issues and to evaluate the convergent and discriminant validity of the measurement model [67]. Moreover, the average variance extracted (AVE) and composite reliability were employed to assess the convergent reliability of the scale items. On the other hand, path analysis is deployed to test the relationship on the hypothesized model as it is shown in Figure 1. Finally, to assess the mediating effects of the stated hypothesis, Baron and Kenny's [68] principles were adopted.

\section{Results}

\subsection{Descriptive Statistics}

This study also employed frequency analysis to analyze the respondents' profile in terms of their gender, age, education, and more. Based on the descriptive analysis, Table 1 indicates that $60.5 \%$ of the survey participants were male while the rest of them (39.5\%) of the female. Frequency analysis 
indicated that the overwhelming majority of the participants were young people (82.9\%), 26 years old and younger. Furthermore, a large group of them were holding a bachelor's degree $(68.8 \%)$, and an overwhelming number of them were single (90.6\%). Finally, when we look at the income level, we see that $52.7 \%$ of the respondents had income level under $\$ 9999$ and only a total of $4 \%$ had $\$ 50,000$ and over.

Table 1. Demographic profile.

\begin{tabular}{|c|c|c|}
\hline & Frequency & Valid Percent (\%) \\
\hline \multicolumn{3}{|l|}{ Gender } \\
\hline Male & 124 & 60.5 \\
\hline Female & 81 & 39.5 \\
\hline Total & 205 & 100 \\
\hline \multicolumn{3}{|l|}{ Age } \\
\hline Under 20 & 37 & 18.0 \\
\hline $21-25$ & 133 & 64.9 \\
\hline $26-30$ & 21 & 10.2 \\
\hline $31-35$ & 10 & 4.9 \\
\hline Over 35 & 4 & 2.0 \\
\hline Total & 205 & 100 \\
\hline \multicolumn{3}{|l|}{ Education } \\
\hline Associate Degree & 26 & 12.7 \\
\hline Bachelor's Degree & 141 & 68.8 \\
\hline Higher Degree & 38 & 18.5 \\
\hline Total & 205 & 100 \\
\hline \multicolumn{3}{|l|}{ Marital Status } \\
\hline Single & 186 & 90.7 \\
\hline Married & 9 & 4.4 \\
\hline Widowed & 5 & 2.4 \\
\hline Divorced & 5 & 2.4 \\
\hline Total & 205 & 100 \\
\hline \multicolumn{3}{|l|}{ Income } \\
\hline Less than $\$ 9999$ & 108 & 52.7 \\
\hline$\$ 10,000-\$ 19,999$ & 42 & 20.5 \\
\hline$\$ 20,000-\$ 29,999$ & 31 & 15.1 \\
\hline$\$ 30,000-\$ 39,999$ & 6 & 2.9 \\
\hline$\$ 40,000-\$ 49,999$ & 14 & 6.8 \\
\hline$\$ 50,000-\$ 59,999$ & 2 & 1.0 \\
\hline$\$ 60,000$ or More & 2 & 1.0 \\
\hline Total & 205 & 100 \\
\hline
\end{tabular}

\subsection{Psychometric Properties of the Measures}

Reliability of measured constructs and items that are responded to by the participants in a developed model should be internally consistent and significantly correlated to generate a high level of reliable outputs. Hence, the constructs of the model were assessed in terms of how consistent and adequate they were from the reliability, convergent validity, and discriminant validity perspectives. In light of this brief information, as it is shown in Table 2, the composite reliability score is above the benchmark level 70, which can be interpreted as the degree of internal consistency being reliable, and there not being an issue or error between the measured items [69].

Confirmatory factor analysis is used to assess each variable of the hypothesized model. As shown in the results in Table 2, the items for each construct were significantly related to the given constructs. According to Anderson and Gerbing [70], all $t$-values above 2.00 are accepted as significant scores. As it is depicted in Table 2, standardized loading estimates are between 60 and 93 and all $t$-values are 
not smaller than 2.00. Moreover, the average variance extracted (AVE) for each measured variable was more significant than the minimum threshold of 50. In other words, all these scores illustrated that there were neither convergent validity nor discriminant issues on the given constructs of this study $[63,69-71]$

Table 2. Scale items, reliabilities, and confirmatory factor analysis results.

\begin{tabular}{|c|c|c|c|c|}
\hline Scale Items & $t$-Values & Standardized Loadings & CR & AVE \\
\hline Information Quality & & & 0.80 & 0.63 \\
\hline InQlty1 "VR provides the precise information I need." & 30.45 & 0.84 & & \\
\hline InQlty2 "VR provides sufficient information" & 20.26 & 0.79 & & \\
\hline InQlty3 "VR provides up-to-date information." & 26.71 & 0.81 & & \\
\hline InQlty4 "VR provides reliable and useful information." & 11.23 & 0.72 & & \\
\hline System Quality & & & 0.84 & 0.68 \\
\hline SysQlty5 "VR is user-friendly." & 36.99 & 0.88 & & \\
\hline SysQlty6 "VR is easy to use" & 25.37 & 0.86 & & \\
\hline SysQlty7 (R) "VR is usable." & 19.61 & 0.81 & & \\
\hline Service Quality & & & 0.70 & 0.56 \\
\hline SerQlty8 "VR has a problem-solving mechanism service." & 5.97 & 0.60 & & \\
\hline SerQlty9 "VR makes you feel safe with given activities." & 19.97 & 0.81 & & \\
\hline SerQlty 10 "VR service gives me individual attention." & 25.66 & 0.85 & & \\
\hline Satisfaction & & & 0.81 & 0.72 \\
\hline Sat11 "I am satisfied with the VR." & 41.90 & 0.86 & & \\
\hline Sat 12 (R) "I am satisfied with the speed of the VR." & 15.78 & 0.73 & & \\
\hline Sat 13 "I am satisfied with the functions provided by the VR." & 34.64 & 0.84 & & \\
\hline Sat14 "I am satisfied with the quality of information available on the VR." & 36.48 & 0.85 & & \\
\hline Visit intention & & & 0.89 & 0.82 \\
\hline VisInt15 "I expect to visit [Paris] in the future." & 22.35 & 0.86 & & \\
\hline VisInt16 "It is likely that I visit [Paris] in the future." & 54.11 & 0.91 & & \\
\hline VisInt17 "I can see myself visiting [Paris] in the future." & 98.06 & 0.93 & & \\
\hline
\end{tabular}

Notes: All items are measured on five-point Likert scales ranging from $1=$ strongly disagree to $5=$ strongly agree. All loadings are significant at the 0.01 level or better. All internal reliability estimates are above the 0.70 cut-off value.

Table 3 demonstrates the measurement results of study constructs in terms of their correlations, means, standard deviations, and square roots. These measurement results display that all direct relations were significant. The composite score was calculated by summing and obtaining the average of all the items of each construct. Since the correlation coefficient was smaller than 0.90, all the constructs differ from each other [72]. Table 3 also demonstrates that there was not an issue with discriminant validity; in other words, the study constructs were not correlated variables. Table 3 also depicts that the correlations of the study measures ranged from 0.213 (service quality and visit intention) to 0.467 (information quality and satisfaction). Specifically, information quality has the highest significant association with satisfaction $(r=0.467 ; p<0.01)$. Furthermore, system quality and service quality also had significant impact on satisfaction ( $\mathrm{r}=0.403 ; p<0.01) ;(\mathrm{r}=0.376 ; p<0.01)$. Again, as shown in Table 3, there was a significant positive correlation among satisfaction and visit intention $(\mathrm{r}=0.331 ; p<0.01)$. On the other hand, the accepted benchmark for the tolerance values is 0.10 [67] and Table 3 depicts that none of the variance inflation factor (VIF) values exceeded 0.10. Lastly, Table 3 also includes the means and standard deviations of the composite scores.

Table 3. Correlations, means, standard deviations, and square roots.

\begin{tabular}{ccccccc}
\hline Scale & $\mathbf{1}$ & $\mathbf{2}$ & $\mathbf{3}$ & $\mathbf{4}$ & $\mathbf{5}$ & VIF \\
\hline 1. Information Quality & 0.78 & & & & & 1383 \\
2. System Quality & $0.403^{* *}$ & 0.81 & & & & 1352 \\
3. Service Quality & $0.400^{* *}$ & $0.424^{* *}$ & 0.76 & & & 1259 \\
4. Satisfaction & $0.467^{* *}$ & $0.403^{* *}$ & $0.376^{* *}$ & 0.8 & & 1000 \\
5. Visit Intention & $0.291^{* *}$ & $0.405^{* *}$ & $0.213^{*}$ & $0.331^{* *}$ & 0.7 & \\
Mean & 3.75 & 4.28 & 3.81 & 3.92 & 4.17 & \\
Standard deviation & 0.88 & 0.86 & 0.92 & 0.96 & 1.01 & \\
\hline
\end{tabular}

Notes: $n=205 .{ }^{* *}$ Correlation is significant at the 0.01 level; * correlation is significant at the 0.05 level. Correlation without an asterisk is insignificant. The results regarding variance inflation factors (VIF) did not demonstrate any problems of multicollinearity. The square root of AVE is in the diagonal. 


\subsection{Hypotheses Testing}

This study employed a PLS path analysis method to test the hypothesized relationships. A bootstrapping technique was utilized to assess the $t$-statistics and to discover the path significance $[63,65]$. Besides that, Table 4 also demonstrates the path coefficients, their significance, and the $R^{2}$ values of endogenous variables.

Table 4. Path analysis results.

\begin{tabular}{|c|c|c|c|}
\hline Control Variables and Hypothesized Relationships & Path Coefficients & $t$-Values & Results \\
\hline \multicolumn{4}{|l|}{ (I) Impact of information quality } \\
\hline \multicolumn{4}{|l|}{ Control Variables } \\
\hline Gender & -0.06 & 0.46 & \\
\hline Education & 0.09 & 0.72 & \\
\hline Age & -0.10 & 0.8 & \\
\hline Marital status & -0.03 & 0.3 & \\
\hline Income & -0.02 & 0.22 & \\
\hline \multicolumn{4}{|l|}{ Hypotheses } \\
\hline H1: INQLTY $\rightarrow$ SAT & 0.42 & $5.23 *$ & \\
\hline \multicolumn{4}{|l|}{ Explained Variance $\mathrm{R}^{2}=0.18 \%$} \\
\hline$\Delta R^{2}=$ no significant change & & & Supported \\
\hline \multicolumn{4}{|l|}{$\mathrm{F}=0.260^{*}$} \\
\hline \multicolumn{4}{|l|}{ Mediating effect: } \\
\hline & 0.33 & $2.64 *$ & \\
\hline & \multicolumn{2}{|c|}{ (II) Impact of system quality } & Supported \\
\hline \multicolumn{4}{|l|}{$\begin{array}{l}\text { Control Variables } \\
\text { Gender }\end{array}$} \\
\hline Education & -0.04 & 0.36 & \\
\hline Age & -0.01 & 0.14 & \\
\hline Marital status & -0.07 & 0.63 & \\
\hline Income & -0.01 & 0.15 & Supported \\
\hline Hypothesis & 0.01 & 0.19 & \\
\hline \multicolumn{4}{|l|}{ H2: SYSQLTY $\rightarrow$ SAT } \\
\hline \multirow{2}{*}{\multicolumn{4}{|c|}{$\begin{array}{l}\text { Explained Variance } R^{2}=0.18 \% \\
\Delta \mathrm{R}^{2}=\text { no significant change }\end{array}$}} \\
\hline & & & \\
\hline \multicolumn{4}{|l|}{ Mediating effect: } \\
\hline \multicolumn{4}{|l|}{ H5b: SYSQLTY $\rightarrow$ SAT $\rightarrow$ VISINT } \\
\hline \multirow{2}{*}{\multicolumn{4}{|c|}{ Control Variables }} \\
\hline & & & \\
\hline & & & Supported \\
\hline \multicolumn{4}{|l|}{$\begin{array}{l}\text { Gender } \\
\text { Education }\end{array}$} \\
\hline Age & -0.03 & 0.34 & \\
\hline Marital status & 0.01 & 0.09 & \\
\hline Income & -0.09 & 0.81 & \\
\hline Hypothesis & 0.03 & 0.2 & \\
\hline H3: SERQLTY $\rightarrow$ SAT & -0.02 & 0.31 & \\
\hline \multicolumn{4}{|l|}{ Explained Variance $R^{2}=0.16 \%$} \\
\hline $\begin{array}{c}\Delta \mathrm{R}^{2}=\text { no significant change } \\
\mathrm{F}=0.289^{*}\end{array}$ & 0.4 & $3.75^{*}$ & \\
\hline \multicolumn{4}{|l|}{ Mediating effect: } \\
\hline \multirow{2}{*}{\multicolumn{4}{|c|}{$\begin{array}{l}\text { H5c: SERQLTY } \rightarrow \text { SAT } \rightarrow \text { VISINT } \\
\text { (IV) Impact of satisfaction }\end{array}$}} \\
\hline & & & \\
\hline \multicolumn{4}{|l|}{ Control Variables } \\
\hline Gender & 0.05 & 0.59 & \\
\hline Education & 0.07 & 0.62 & \\
\hline Age & 0.1 & 1.01 & \\
\hline Marital status & -0.03 & 0.38 & Supported \\
\hline Income & 0.06 & 0.72 & \\
\hline \multicolumn{4}{|l|}{ Hypothesis } \\
\hline H4: SAT $\rightarrow$ VISINT & 0.41 & $4.31 *$ & \\
\hline Explained Variance $\mathrm{R}^{2}=0.17 \%$ & & & \\
\hline $\begin{array}{l}\Delta \mathrm{R}^{2}=\text { no significant change } \\
\mathrm{F}=0.286^{*}\end{array}$ & & & \\
\hline
\end{tabular}

Notes: $n=205$; ${ }^{*}$ The $t$-values demonstrate a statistically significant relationship at the 0.05 level or better. The other $t$-values without any asterisks are insignificant.

Hypothesis 1 proposed that information quality has a significant positive effect on satisfaction. As shown in Table 4, the path from information quality to satisfaction was significant and positive ( $\beta=0.42, t=5.23, p<0.05)$. Hypothesis 1 was, therefore, supported.

Information quality explained $18 \%$ of the variance in satisfaction. None of the control variables had a statistically significant effect when included in the model. 
Hypothesis 2 suggested that system quality has a significant positive effect on satisfaction. As shown in Table 4, the path from system quality to satisfaction was significant and positive $(\beta=0.43$, $p<0.05)$. Hypothesis 2 was, therefore, supported. System quality explained $18 \%$ of the variance in satisfaction. Again, none of the control variables had a statistically significant effect when included in the model.

Hypothesis 3 suggested that service quality has a significant positive effect on satisfaction. As shown in Table 4, the path from service quality to satisfaction was significant and positive $(\beta=0.40$, $t=3.75 p<0.05$ ). Hypothesis 3 was, therefore, supported. Service quality explained $16 \%$ of the variance in satisfaction. Again, none of the control variables had a statistically significant effect when included in the model.

Hypothesis 4 suggested that satisfaction has a significant positive effect on visit intention. As shown in Table 4, the path from satisfaction to visit intention was significant and positive $(\beta=0.41, t=4.31$ $p<0.05)$. Hypothesis 4 was, therefore, supported. Satisfaction explained $17 \%$ of the variance in visit intention. Again, none of the control variables had a statistically significant effect when included in the model.

The path analysis indicates that satisfaction mediates the impact of information quality on visit intention $(t=2.64, p<0.05)$, which was a full mediation. This is because when information quality and satisfaction are controlled, we see that the previously significant relationship between the independent and dependent variables was nonsignificant $(\beta=0.16, t=1.36, p<0.05)$. Thus, H5a was supported.

The result indicates that satisfaction partially mediates the impact of system quality on visit intention $(\beta=3.32, p<0.05)$, because when information quality and satisfaction are controlled, we see that the previously significant relationship between the independent and dependent variables was still significant $(\beta=0.20, t=3.25, p<0.05)$. Thus, H5b was supported.

In testing H5c, one of the mediation rules (Baron and Kenny, 1986) did not occur. As such, a direct link must be established between the independent and dependent variables to ensure there is a relationship to be mediated. Second, a direct relationship must be established between the independent and mediator variable. Third, the mediator must be shown to be related to the dependent variable. Last, the relationship between the independent and dependent variables must be significantly reduced when the mediator is added. The relationships between the independent and dependent variables, as well as between the independent and mediating variables, should be theory-based and supported by the literature. The results show that no significant relationship between service quality and visit intention was found $(\beta=0.22 t=1.44)$. Thus, it could not be applicable to measure the mediating role of satisfaction in the relationship between service quality and visit intention. Thus, $\mathrm{H} 5 \mathrm{c}$ was not applicable for the current study.

\section{Conclusions}

This study examined what feature(s) of virtual reality determines individual visit intention towards a touristic product. Innovation has been a significant catalytic power for technological advancements for public and private organizations. Even though virtual reality is not only the latest technology, but has a future through innovative originated technological devices, it offers myriad opportunities in this highly demanding, challenging, and competitive digital automatized era for the tourism industry. Organizations invest some of their considerable amount of capital for smart-led growth tools/devices such as artificial intelligence, robots, virtual reality, and research efforts securing their firms for plans. However, selecting the right technology requires understanding the needs of the sector in depth and analyzing the features of the product for its quality of system, service, and information quality. Considering all these factors is vital since the life cycles of new technologies are getting shorter than one can imagine. Moreover, innovative technology has an enormous impact on the nations' economic progress and the welfare of the citizens in terms of their lifestyle, well-being, and fair income distribution. VR, with its great exciting functionalities, offers excellent potential to add significant gains to both public and private organizations. 
This study also aimed to discover the impacts of virtual reality on tourism product selection by implementing the Information Systems Success Model. The IS Success Model helped to broaden our understanding between the relationship of technology and the tourism industry by focusing on the system, service, and information quality dimensions of VR. This study illustrated that the measured parameters influence the user's attitude changes in tourism destination selection process. It is discovered that VR offers a considerable amount of positive impact to influence tourists' perceptions about the destinations to which the users are being transported virtually.

VR has a significant impact on visitation purposes towards a destination, as previous studies such as Guttentag [8] and Wang, Wang [40] have revealed. As aforementioned, the more concise information, more robust system, and reliable service are provided, the higher perceived satisfaction is achieved. The IS success model is applied in many studies across different disciplines to discover the essential factor that leads to the desired goal of a study. However, this study investigated how VR impacts on user satisfaction and the intention to visit a touristic destination using the IS success model. As Huang, Backman [73] stated, discovering the factors that lead to influencing potential user attitudes and intention is a crucial turning point before it is applied in the tourism sector.

Therefore, this study is the first empirical study in the context of VR which applied the IS success model to identify these factors and test the relationship between information quality, system quality, service quality, and user satisfaction. On the other hand, applying the IS success model into this VR study is a significant contribution of this research. Next, this study is also one of the first empirical studies which tested the VR in a real-life environment. This realistic approach helped to understand what are the significant advantages and challenges of using VR as a substitutional marketing tool in the tourism sector in terms of its implication and application to enhance the user intention.

The first finding of this empirical study confirmed that there is a significant positive relationship with information quality and user satisfaction. More significant given quality information meant more significant satisfaction perceived by the user, which is consistent with the previous findings (Seddon, Kiew [46] and [44]). The second finding showed that there is also a significant positive relationship between system quality and user satisfaction that also validated Seddon, Kiew [46], and Seddon and Kiew [45]. In other words, as potential users interact with a higher quality system, their perceived satisfaction increases more significantly than otherwise. The third finding indicated that service quality also has a significant positive relationship with user satisfaction that is consistent with the previous studies such as Seddon, Kiew [46] and Wang and Liao. Next, this study showed that satisfaction has an essential role as a factor, and it does have a positive influence on visitation intention. This paper also indicates that higher satisfaction results in greater visitation intention, which is in line with the findings of Chiu, Chiu [34]

On the other hand, this study indicated that satisfaction as a mediator had a full mediation effect between information quality and visitation intention. In other words, information quality is one of the most critical factors that led to visiting intention through user satisfaction. Furthermore, satisfaction partially mediated the relationship between system quality and visit intention. As aforementioned before, the last hypothesis (H5c) of this study was not applicable for the current study. A slight relationship seems but not at the significant level. This does not mean that the same result will occur in other contexts.

\section{Implications and Recommendations}

This paper demonstrated that there are a considerable number of theoretical, practical, and social implications of the virtual reality environment in the context of tourism. On a theoretical foundation, the study contributes to the literature in two significant areas. First, this study adds a significant contribution to the existing literature with its factual findings, which were obtained as a result of conducting an empirical study in an authentic environment. This study presents useful practicable information to the practitioners, including business owners and VR researchers. 
Second, using the IS Success Model, it is discovered what factors influence the user satisfaction that triggers potential travellers' intention towards a destination. On the practical side, this study demonstrated that tourism planners, managers, and authorities should consider VR as one of the core emerging technologies that have compelling and promising features for the tourism sector. Tourism developers can promote their touristic attractions with this highly effective innovative technological device. Lastly, this study also showed that private and public organizations which integrate effective emerging technologies would most likely outperform the ones that undervalue the impacts of the sophisticated technological mediums. This study also exemplified that implementing emerging technologies is closely related to the socioeconomic status of societies. The more effective innovative tools which are assessed based on its quality of information, quality of service, and quality of the system, the higher likelihood there is of tourism-based economic affairs.

Assessing the initial presence for the destination using the VR program based on the customers' preferences is not an easy task and process. Both VR hardware and software should enable quality of information, effective system, and service to influence customers' satisfaction and attitude change towards visit intention. Future studies may also need to ensure that the system is designed, prepared, and offered by targeting all level of individuals while including ones with minimal technological skills. Thus, organizations, developers, and practitioners aligned with the researchers need to consider the accurate and objective value of this emerging technology to achieving the organizations' and customers' total satisfaction.

On the other hand, the post-coronavirus term indicates that the way we live, work, socialize, educate, and travel will not be the same anymore. VR seems to be one of the most important innovative technologies that will transform the way we are travelling. So, this study offers an alternative way to visit the attractions around the globe as people are forbidden to go out, and it poses high risks for their health.

\section{Limitation}

There are some limitations of this study that can be considered by future researchers. First of all, data collection tool could be prepared in various languages such as Russian and Arabic to increase the number of participants. On the other hand, instead of using convenience sampling, future studies can be designed as one of the probability sampling methods. Next, using the different approaches, models, and variables can also help to identify what potential consumers' attitudes are and how they change. Finally, the majority of the focus group was limited to participants who were from Middle Eastern and African countries, which limited collecting data from a broader geographic area.

Author Contributions: The conceptualization of this study was developed by H.A., A.O. and A.Y. The methodology was designed by A.Y. and H.A., but analyzed and interpreted by M.D. using the PLS. Validation of the findings was checked by H.A., while writing, reviewing, and editing of the manuscript were performed by A.O. and A.Y. All authors have read and agreed to the published version of the manuscript.

Funding: This research received no external funding.

Conflicts of Interest: The authors declare no conflict of interest.

\section{References}

1. Katircioglu, S.T.; Arasli, H.; Ekiz, E.H. Trends in tourism in North Cyprus: A historical perspective. E-Rev. Tour. Res. 2007, 5, 37-46.

2. Katircioglu, S.T. International tourism, higher education and economic growth: The case of North Cyprus. World Econ. 2010, 33, 1955-1972. [CrossRef]

3. Roudi, S.; Arasli, H.; Akadiri, S.S. New insights into an old issue-examining the influence of tourism on economic growth: Evidence from selected small island developing states. Curr. Issues Tour. 2019, 22, 1280-1300. [CrossRef]

4. Altinay, L. Possible impacts of a federal solution to the Cyprus problem on the tourism industry of North Cyprus. Int. J. Hosp. Manag. 2000, 19, 295-309. [CrossRef] 
5. Okumus, F.; Altinay, M.; Arasli, H. The impact of Turkey's economic crisis of February 2001 on the tourism industry in Northern Cyprus. Tour. Manag. 2005, 26, 95-104. [CrossRef]

6. Alipour, H.; Kilic, H. An institutional appraisal of tourism development and planning: The case of the Turkish Republic of North Cyprus (TRNC). Tour. Manag. 2005, 26, 79-94. [CrossRef]

7. Steinicke, F. Being Really Virtual: Immersive Natives and the Future of Virtual Reality; Springer: Berlin, Germany, 2016.

8. Guttentag, D.A. Virtual reality: Applications and implications for tourism. Tour. Manag. 2010, 31, 637-651. [CrossRef]

9. Adamuthe, A.C.; Thampi, G.T. Technology forecasting: A case study of computational technologies. Technol. Forecast. Soc. Chang. 2019, 143, 181-189. [CrossRef]

10. Escobar-Rodríguez, T.; Carvajal-Trujillo, E. Online purchasing tickets for low cost carriers: An application of the unified theory of acceptance and use of technology (UTAUT) model. Tour. Manag. 2014, 43, 70-88. [CrossRef]

11. Vial, G. Understanding digital transformation: A review and a research agenda. J. Strateg. Inf. Syst. 2019, 28, 118-144. [CrossRef]

12. Horan, P. Virtual reality applications in the hospitality/tourism industry. Hosp. Inf. Technol. Assoc. Electron. J. 1996, 1, 1-7.

13. Wiltshier, P.; Clarke, A. Virtual cultural tourism: Six pillars of VCT using co-creation, value exchange and exchange value. Tour. Hosp. Res. 2017, 17, 372-383. [CrossRef]

14. Wang, D.; Park, S.; Fesenmaier, D.R. The role of smartphones in mediating the touristic experience. J. Travel Res. 2012, 51, 371-387. [CrossRef]

15. Doolin, B.; Burgess, L.; Cooper, J. Evaluating the use of the Web for tourism marketing: A case study from New Zealand. Tour. Manag. 2002, 23, 557-561. [CrossRef]

16. Chung, N.; Lee, H.; Kim, J.-Y.; Koo, C. The role of augmented reality for experience-influenced environments: The case of cultural heritage tourism in Korea. J. Travel Res. 2018, 57, 627-643. [CrossRef]

17. Jung, T.; tom Dieck, M.C.; Lee, H.; Chung, N. Effects of virtual reality and augmented reality on visitor experiences in museum. In Information and Communication Technologies in Tourism 2016; Springer: Cham, Switzerland, 2016; pp. 621-635.

18. Wei, W.; Qi, R.; Zhang, L. Effects of virtual reality on theme park visitors' experience and behaviors: A presence perspective. Tour. Manag. 2019, 71, 282-293. [CrossRef]

19. Hudson, S.; Matson-Barkat, S.; Pallamin, N.; Jegou, G. With or without you? Interaction and immersion in a virtual reality experience. J. Bus. Res. 2019, 100, 459-468. [CrossRef]

20. Tussyadiah, I.P.; Wang, D.; Jung, T.H.; tom Dieck, M.C. Virtual reality, presence, and attitude change: Empirical evidence from tourism. Tour. Manag. 2018, 66, 140-154. [CrossRef]

21. Delone, W.H.; McLean, E.R. The DeLone and McLean Model of Information Systems Success: A Ten-Year Update. J. Manag. Inf. Syst. 2003, 19, 9-30.

22. Yim, M.Y.-C.; Park, S.-Y. "I am not satisfied with my body, so I like augmented reality (AR)": Consumer responses to AR-based product presentations. J. Bus. Res. 2019, 100, 581-589. [CrossRef]

23. Ludlow, B.L. Virtual reality: Emerging applications and future directions. Rural Spec. Educ. Q. 2015, 34, 3-10. [CrossRef]

24. Laurell, C.; Sandström, C.; Berthold, A.; Larsson, D. Exploring barriers to adoption of Virtual Reality through Social Media Analytics and Machine Learning-An assessment of technology, network, price and trialability. J. Bus. Res. 2019, 100, 469-474. [CrossRef]

25. LaValle, S.M.; Yershova, A.; Katsev, M.; Antonov, M. Head tracking for the Oculus Rift. In Proceedings of the 2014 IEEE International Conference on Robotics and Automation (ICRA), Hong Kong, China, 31 May-7 June 2014; pp. 187-194.

26. Avidar, R. Engagement, interactivity, and diffusion of innovations. Handb. Commun. Engagem. 2018, 505.

27. Cheong, R. The virtual threat to travel and tourism. Tour. Manag. 1995, 16, 417-422. [CrossRef]

28. Diemer, J.; Alpers, G.W.; Peperkorn, H.M.; Shiban, Y.; Mühlberger, A. The impact of perception and presence on emotional reactions: A review of research in virtual reality. Front. Psychol. 2015, 6, 26. [CrossRef]

29. Carassa, A.; Morganti, F.; Tirassa, M. Movement, action, and situation: Presence in virtual environments. In Proceedings of the 7th Annual International Workshop on Presence, Valencia, Spain, 13-15 October 2004; pp. 7-12. 
30. Burdea Grigore, C.; Coiffet, P. Virtual Reality Technology; Wiley-Interscience: London, UK, 1994.

31. Marchiori, E.; Niforatos, E.; Preto, L. Analysis of users' heart rate data and self-reported perceptions to understand effective virtual reality characteristics. Inf. Technol. Tour. 2018, 18, 133-155. [CrossRef]

32. Turizm İstatistikleri. Available online: http://turizmplanlama.gov.ct.tr/TUR\%C4\%B0ZM- $\%$ C4\%B0STAT\% C4\%B0ST\%C4\%B0KLER\%C4\%B0 (accessed on 10 August 2020).

33. Petter, S.; DeLone, W.; McLean, E. Measuring information systems success: Models, dimensions, measures, and interrelationships. Eur. J. Inf. Syst. 2008, 17, 236-263. [CrossRef]

34. Chiu, C.M.; Chiu, C.S.; Chang, H.C. Examining the Integrated Influence of Fairness and Quality on Learners' Satisfaction and Web-Based Learning Continuance Intention. Inf. Syst. J. 2007, 17, 271-287. [CrossRef]

35. Ojo, A.I. Validation of the DeLone and McLean Information Systems Success Model. Healthc. Inform. Res. 2017, 23, 60-66. [CrossRef]

36. Gorla, N.; Somers, T.M.; Wong, B. Organizational Impact of System Quality, Information Quality, and Service Quality. J. Strateg. Inf. Syst. 2010, 19, 207-228. [CrossRef]

37. Seddon, P.B. A respecification and extension of the DeLone and McLean model of IS success. Inf. Syst. Res. 1997, 8, 240-253. [CrossRef]

38. Goodhue, D.L.; Thompson, R.L. Task-Technology Fit and Individual Performance. MIS Q. 1995, $213-236$. [CrossRef]

39. Rai, A.; Lang, S.S.; Welker, R.B. Assessing the validity of IS success models: An empirical test and theoretical analysis. Inf. Syst. Res. 2002, 13, 50-69. [CrossRef]

40. Wang, Y.-S.; Wang, H.-Y.; Shee, D.Y. Measuring E-Learning Systems Success in an Organizational Context: Scale Development and Validation. Comput. Hum. Behav. 2007, 23, 1792-1808. [CrossRef]

41. Shannon, C.E.; Weaver, W. The Mathematical Theory of Communication; University of Illinois Press: Urbana, IL, USA, 1949.

42. Mason, R.O. Measuring information output: A communication systems approach. Inf. Manag. 1978, 1, 219-234. [CrossRef]

43. Mihelj, M.; Novak, D.; Beguš, S. Virtual Reality Technology and Applications; Springer: Dordrecht, The Netherlands; Heidelberg, Germany; London, UK; New York, NY, USA, 2014.

44. Zaied, A.N.H. An integrated success model for evaluating information system in public sectors. J. Emerg. Trends Comput. Inf. Sci. 2012, 3, 814-825.

45. Seddon, P.; Kiew, M.-Y. A partial test and development of DeLone and McLean's model of IS success. Australas. J. Inf. Syst. 1994, 4, 1. [CrossRef]

46. Yuce, A.; Abubakar, A.M.; Ilkan, M. Intelligent Tutoring Systems and Learning Performance: Applying Task-technology Fit and IS Success Model. Online Inf. Rev. 2019. [CrossRef]

47. Collier, J.E.; Bienstock, C.C. Measuring service quality in e-retailing. J. Serv. Res. 2006, 8, 260-275. [CrossRef]

48. Bailey, J.E.; Pearson, S.W. Development of a tool for measuring and analyzing computer user satisfaction. Manag. Sci. 1983, 29, 530-545. [CrossRef]

49. Lu, I.-Y.; Kuo, T.; Lee, W.-P. Toward User Satisfaction of E-Learning: The Roles of Qualities, Social Influence and User Beliefs. Int. Inf. Inst. (Tokyo) Inf. 2012, 15, 4855.

50. Oliver, R.L.; Swan, J.E. Consumer perceptions of interpersonal equity and satisfaction in transactions: A field survey approach. J. Mark. 1989, 53, 21-35. [CrossRef]

51. Au, N.; Ngai, E.W.; Cheng, T.E. A critical review of end-user information system satisfaction research and a new research framework. Omega 2002, 30, 451-478. [CrossRef]

52. Doll, W.J.; Torkzadeh, G. The measurement of end-user computing satisfaction. MIS Q. 1988, 12, $259-274$. [CrossRef]

53. Shirani, A.; Aiken, M.; Reithel, B. A model of user information satisfaction. Acm Sigmis Database Database Adv. Inf. Syst. 1994, 25, 17-23. [CrossRef]

54. Bhattacherjee, A. Understanding information systems continuance: An expectation-confirmation model. MIS Q. 2001, 351-370. [CrossRef]

55. LaValle, S. Virtual Real. 2016. Available online: http://vr.cs.uiuc.edu/ (accessed on 10 August 2020).

56. Google Maps. Google. Available online: https://www.google.com/maps/place/Famagusta/ (accessed on 10 August 2020).

57. Urbach, N.; Smolnik, S.; Riempp, G. An Empirical Investigation of Employee Portal Success. J. Strateg. Inf. Syst. 2010, 19, 184-206. [CrossRef] 
58. Liaw, S.-S.; Chen, G.-D.; Huang, H.-M. Users' Attitudes toward Web-Based Collaborative Learning Systems for Knowledge Management. Comput. Educ. 2008, 50, 950-961. [CrossRef]

59. Liaw, S.-S.; Huang, H.-M.; Chen, G.-D. Surveying Instructor and Learner Attitudes toward E-Learning. Comput. Educ. 2007, 49, 1066-1080. [CrossRef]

60. Kozak, M.; Rimmington, M. Tourist satisfaction with Mallorca, Spain, as an off-season holiday destination. J. Travel Res. 2000, 38, 260-269. [CrossRef]

61. Tussyadiah, I.P. Factors of satisfaction and intention to use peer-to-peer accommodation. Int. J. Hosp. Manag. 2016, 55, 70-80. [CrossRef]

62. Chin, W.W. The partial least squares approach to structural equation modeling. Mod. Methods Bus. Res. 1998, 295, 295-336.

63. Wold, H. Soft modeling: The basic design and some extensions. Syst. Under Indirect Obs. 1982, 2, 343.

64. Hair Jr, J.F.; Hult, G.T.M.; Ringle, C.; Sarstedt, M. A Primer on Partial Least Squares Structural Equation Modeling (PLS-SEM); Sage Publications, Inc.: Thousand Oaks, CA, USA, 2014.

65. MacKenzie, S.B.; Podsakoff, P.M.; Rich, G.A. Transformational and transactional leadership and salesperson performance. J. Acad. Mark. Sci. 2001, 29, 115. [CrossRef]

66. Hair, J.F.; Anderson, R.E.; Babin, B.J.; Black, W.C. Multivariate Data Analysis: A Global Perspective; Pearson Upper Saddle River: Hoboken, NJ, USA, 2010; Volume 7.

67. Baron, R.M.; Kenny, D.A. The moderator-mediator variable distinction in social psychological research: Conceptual, strategic, and statistical considerations. J. Personal. Soc. Psychol. 1986, 51, 1173. [CrossRef]

68. Fornell, C.; Larcker, D.F. Evaluating structural equation models with unobservable variables and measurement error. J. Mark. Res. 1981, 39-50. [CrossRef]

69. Anderson, J.C.; Gerbing, D.W. Structural equation modeling in practice: A review and recommended two-step approach. Psychol. Bull. 1988, 103, 411. [CrossRef]

70. Bagozzi, R.P.; Yi, Y. On the Evaluation of Structural Equation Models. J. Acad. Mark. Sci. 1988, 16, 74-94. [CrossRef]

71. Tabachnick, B.G.; Fidell, L.S. Using Multivariate Statistics; Allyn \& Bacon/Pearson Education: Boston, MA, USA, 2007.

72. Huang, Y.C.; Backman, K.F.; Backman, S.J.; Chang, L.L. Exploring the implications of virtual reality technology in tourism marketing: An integrated research framework. Int. J. Tour. Res. 2016, 18, 116-128. [CrossRef]

73. Wang, Y.-S.; Liao, Y.-W. Assessing eGovernment Systems Success: A Validation of the DeLone and McLean Model of Information Systems Success. Gov. Inf. Q. 2008, 25, 717-733. [CrossRef] 